\title{
Relações entre a Compreensão de Leitura e as Habilidades Metalinguísticas
}

\author{
Acácia Aparecida Angeli dos Santos ${ }^{1}$ https://orcid.org/0000-0002-8599-7465 \\ Adriana Satico Ferraz ${ }^{1}$ https://orcid.org/0000-0002-9856-0094 \\ Fabián Javier Marín Rueda1 https://orcid.org/0000-0001-5173-0802
}

\begin{abstract}
Resumo
Por ser a compreensão de leitura uma habilidade fundamental no contexto escolar, este estudo se propôs ao exame das relações entre ela e as habilidades metalinguísticas - consciência morfológica e consciência metatextual. Secundariamente, pretendeu-se explorar possíveis diferenças dos construtos nas variáveis sexo e ano escolar. Participaram do estudo 71 alunos do ensino fundamental I $\left(2^{\circ}\right.$ ao $5^{\circ}$ ano) de uma escola municipal situada no interior de São Paulo. Os instrumentos utilizados foram dois textos de Cloze, as Tarefas de Consciência Morfológica e o Questionário de Avaliação da Consciência Metatextual. Os resultados apontaram para a identificação de correlações positivas, de magnitude moderada a forte entre os construtos e a apresentação de maiores médias nas habilidades avaliadas mediante o avanço dos anos escolares. Sugere-se a continuidade dos estudos que objetivem a investigação da compreensão de leitura e das habilidades metalinguísticas, estendendo para as consciências semântica e sintática.
\end{abstract}

Palavras-chave: Compreensão de leitura; consciência morfológica; consciência metatextual.

\section{Relations between Reading Comprehension and Metalinguistic Abilities Psychological}

\begin{abstract}
We consider that reading comprehension is a fundamental skill in the school context, this study aims to examine the relations between it and the metallinguistic abilities - morphological awareness and metatextual awareness. Secondly, it was intended to explore possible differences of the constructs in the variables gender and school year. A total of 71 students from elementary school I (2nd to 5th grade) from a municipal school located in the interior of São Paulo participated in the study. The instruments used were two texts by Cloze, the Morphological Consciousness Tasks and the Metatextual Consciousness Assessment Questionnaire. The results pointed to the identification of positive correlations, of moderate to strong magnitude between the constructs and the presentation of higher averages in the abilities evaluated through the advancement of the school years. We suggest the continuity of studies aimed at the investigation of reading comprehension and metalinguistic skills, extending to the semantic and syntactic consciousness.
\end{abstract}

Keywords: Reading comprehension; morphological awareness; metatextual awareness.

\section{Las Relaciones entre la Comprensión de Lectura y Habilidades Metalingüísticas}

\section{Resumen}

Por ser la comprensión de lectura una habilidad fundamental en el contexto escolar, en este estudio se propone al examen de las relaciones entre ella y las habilidades metalingüísticas - consciencia morfológica y consciencia meta textual. Secundariamente, se pretendió explotar posibles diferencias de los constructos en las variables sexo y año escolar. Participaron del estudio 71 alumnos de la enseñanza primaria I $\left(2^{\circ}\right.$ al $5^{\circ}$ curso) de una escuela municipal ubicada en el interior de São Paulo. Los instrumentos se utilizó dos textos de Cloze, las Tareas de Consciencia Morfológica y el Cuestionario de Evaluación de la Consciencia Meta textual. Los resultados apuntaron para la identificación de correlaciones positivas, de magnitud moderada la fuerte entre los constructos y la presentación de mayores medias en las habilidades evaluadas mediante el avance de los años escolares. Se sugiere la continuidad de los estudios que tengan por objetivo la investigación de la comprensión de lectura y de las habilidades metalingüísticas, extendiendo para las consciencias semántica y sintáctica.

Palabras clave: Comprensión de lectura; consciencia morfológica; consciencia meta textual.

1 Universidade São Francisco, Campinas - SP - Brasil; acacia.santos@usf.edu.br; adrianasatico.as@gmail.com; fabian.rueda@usf.edu.br 


\section{Introdução}

O processo de aquisição e domínio da leitura ocorre comumente nos primeiros anos escolares, por meio do contato do aluno com os conteúdos referentes à instrução formal. A aprendizagem da leitura, apesar de centrar-se em práticas que enfatizam a decodificação, tem por objetivo guiar o aluno a tornar-se um leitor ágil e proficiente mediante estratégias que levam a uma leitura fluente, tais como a realização de inferências e a tomada de decisão (Brasil, 1997). Estes procedimentos visam atingir a compreensão de leitura, habilidade que possibilita a interpretação e apropriação do conteúdo transmitido no texto (Cunha, 2012).

No âmbito escolar, a compreensão de leitura contribui para a aprendizagem dos diversos conteúdos previstos pelo currículo escolar, que tendem a se tornar mais complexos, conforme a progressão dos anos escolares, o que lhe confere importância destacada para o processo de aprendizagem. Além da contribuição para a instrução formal de base, a compreensão de leitura favorece o bom desempenho acadêmico e a inserção do indivíduo no mercado de trabalho, bem como o leva a desenvolver noções mais críticas sobre si mesmo e o ambiente que o cerca, o que favorece a sua participação ativa em sociedade (Brasil, 1997; Cunha \& Santos, 2008; Santos, Boruchovitch, \& Oliveira, 2009; Santos, Primi, Taxa, \& Vendramini, 2002).

Com foco no Ensino Fundamental, Cunha e Santos (2008) discutem acerca da necessidade de avaliação preventiva em compreensão de leitura e a prestação de auxílio ao aluno que apresenta dificuldades nessa habilidade. Nesse sentido, é importante identificar as habilidades linguísticas relacionadas à compreensão de leitura, como é o caso do reconhecimento de palavras (Corso \& Salles, 2009) e as habilidades metalinguísticas, tais como a consciência fonológica (Suehiro \& Santos, 2015) e a consciência morfológica (Mota \& cols., 2009).

Dada a relevância da compreensão de leitura e de outras habilidades relacionadas ao processo de ensino e aprendizagem no contexto escolar, é relevante encontrar formas adequadas de avaliá-las. Nesse sentido, é pertinente frisar a contribuição da Avaliação Psicológica e Educacional, que visa, dentre outros aspectos, a construção, validação e normatização de instrumentos com o propósito de avaliar diferentes construtos e o aprofundamento dos conhecimentos sobre eles (Capovilla, Capovilla, \& Soares, 2004; Lúcio, Moura, Nascimento, \& Pinheiro, 2012). A aplicação de instrumentos auxilia na identificação das dificuldades apresentadas pelo aluno e também na verificação dos componentes atrelados aos processos de escolarização e aprendizagem, o que possibilita a formulação de estratégias para desenvolver tais habilidades, dentre outras intervenções (Cunha, 2012; Santos \& cols., 2002).

Tratando-se da avaliação da compreensão de leitura, Oliveira, Boruchovitch e Santos (2009) e Suehiro e Boruchovitch (2016) assinalam a eficácia do teste de Cloze. Elaborado por Taylor em 1953, esse teste avalia o nível de clareza do leitor quanto à compreensão de leitura, diferin- do dos instrumentos que aferem essa habilidade somente por meio da produção textual. O teste de Cloze baseia-se na estimulação entre a interação do leitor com o conteúdo do texto, relacionado à discriminação em meio à escrita e os aspectos fonológicos das palavras que o compõem, o que leva à sua compreensão. O sistema de resposta deste instrumento também está ligado à complexidade atribuída ao item, que se expressa pelo seu nível de dificuldade. Tal característica requer a mobilização dos fatores intrínsecos do leitor, associados às suas estratégias cognitivas e os fatores extrínsecos, que se refere ao seu conhecimento prévio sobre o conteúdo apresentado no texto e a mobilização de estratégias para o cumprimento dessa tarefa.

Esse instrumento se mostra eficaz como medida da compreensão de leitura, conforme pesquisas brasileiras recentes no contexto escolar (Baliza \& Silva, 2015; Machado \& Capellini, 2016; Santos \& cols., 2009) e acadêmico (Alcará \& Santos, 2015; Santos \& Santos, 2015) e internacional (Torres \& Roig, 2005; Williams, Ari, \& Santamaria, 2011). Ressalta-se, ainda, que o teste de Cloze é um instrumento de fácil aplicação e correção, e de baixo custo, o que o torna uma ferramenta acessível de avaliação.

Para Santos e cols. (2002) as estratégias cognitivas envolvidas na compreensão de leitura decorrem dos processos mentais, com ênfase para a memória de trabalho e de longo prazo. Ambas as memórias permitem o resgate e a ativação de conhecimentos anteriormente armazenados, o que permite o seu processamento durante a leitura, possibilitando a realização de inferências e analogias feitas pelo leitor, resultando na compreensão do texto.

Durante o processo de aprendizagem da leitura e escrita, alguns autores destacam a importância das habilidades metalinguísticas, por possibilitarem que o aluno analise e reflita de forma consciente sobre a linguagem (Barrera \& Maluf, 2003; Brasil, 1997; Gomes \& Boruchovitch, 2009; Spinillo \& Simões, 2003). O desenvolvimento das habilidades metalinguísticas pode ocorrer em situações cotidianas vivenciadas pela criança, que envolvem a comunicação e a reflexão da fala, pelo contato com a instrução formal, em que se identifica uma apropriação gradativa, assim como conforme a progressão dos anos escolares em consonância com o aumento da idade (Albuquerque \& Spinillo, 1997, 1998; Kruk \& Bergman, 2013).

As habilidades metalinguísticas, segundo Gombert (1992), são classificadas em cinco subgrupos de acordo com o direcionamento do foco da criança durante a leitura, a saber, a consciência fonológica (fonema), consciência morfológica (palavra), consciência sintática (sintaxe), consciência pragmática (contexto no qual a linguagem se insere) e a consciência metatextual (texto). Este estudo se centra na investigação da consciência morfológica e metatextual como possíveis habilidades metalinguísticas relacionadas à compreensão de leitura.

A consciência morfológica se caracteriza pela capacidade de refletir sobre os morfemas que constituem a palavra (Mota \& cols., 2013). A morfologia engloba as regras subjacentes aos processos, tanto da formação quanto da concepção de novas palavras, as quais se referem a sua estrutura 
interna, composição e organização dos elementos que as compõem (Basílio, 2009). Essa habilidade metalinguística é associada à aprendizagem da leitura e escrita (Freitas Junior \& Mota, 2015; Miranda \& Mota, 2013; Mota, 2012; Mota, Anibal, \& Lima, 2008) e à compreensão da leitura (Kruk \& Bergman, 2013).

Em termos da relação entre a consciência morfológica e a compreensão de leitura, destacam-se estudos nos quais se utilizaram textos do teste de Cloze para conferir tal associação. Mota e cols. (2009) encontraram correlações positivas, de magnitudes fracas a moderada entre tarefas envolvendo a compreensão de leitura avaliada pelo teste de Cloze e a consciência morfológica em uma amostra de 42 alunos matriculados na $1^{a}$ e $2^{a}$ séries do ensino fundamental (Tarefa de Analogia Gramatical e Cloze 1: $r=0,47$ e Cloze 2: $r=0,52$, sendo $p<0,01$; Associação Morfo-Semântica e Cloze 2: $r=0,36 ; p<0,05)$. Também com alunos do fundamental ( $3^{\circ}$ ao $5^{\circ}$ ano; $\left.n=72\right)$ Guimarães, Paula, Mota e Barbosa (2014) identificaram correlações positivas entre a consciência morfológica e a compreensão de leitura. Essa análise conferiu à consciência morfológica flexional a explicação de $16,3 \%$ da variância na compreensão de leitura e à consciência morfológica derivacional $20,9 \%$. Os resultados de ambas as pesquisas são convergentes ao mostrarem a relevância da consciência morfológica como favorecedora da compreensão da leitura.

Outra habilidade metalinguística a ser destacada é a consciência metatextual, definida como uma habilidade que permite a reflexão e análise por meio do monitoramento intencional do texto, em vias de seus elementos formais, ou seja, a atenção do leitor se volta para os seus aspectos estruturais. De acordo com Gombert (1992), a consciência metatextual favorece que o sujeito tome consciência sobre a estrutura e a organização do texto, passando a identificar e classificar o seu gênero textual. A respeito, Spinillo (2009) ainda salienta que o texto ultrapassa a função de comunicar um assunto ao ser compreendido como um objeto de reflexão.

Gombert (1992) divide o monitoramento empregado na consciência metatextual em três subgrupos, a saber, o monitoramento de coerência, atrelado às variáveis semânticas; o monitoramento de coesão, que engloba as variáveis morfossintáticas e o monitoramento da estrutura, com ênfase para a estrutura textual. Desses três subgrupos emergem duas linhas de pesquisa que se propõem a investigação da consciência metatextual. A primeira aborda os aspectos microlinguísticos, ou seja, os elementos coesivos, como é o caso da pontuação. A outra linha objetiva investigar os aspectos macrolinguísticos, com foco para a organização geral do texto, dividida na verificação da reflexão sobre o seu conteúdo e na diferenciação dos tipos textuais, a partir da estrutura e informações transmitidas pelo texto.

Pesquisas com alunos do primeiro ciclo do ensino fundamental reportam a contribuição da consciência metatextual para a escrita, avaliada por meio de produções de textos narrativos (Santos \& Barrera, 2015), bem como mostram a existência da relação entre a compreensão de textos e a habilidade metatextual aferida por meio da análise de textos narrativos e argumentativos (Spinillo \& Almeida, 2014). No que diz respeito à associação existente entre a compreensão de leitura e a consciência metatextual, Barboza (2014) e Cunha e Santos (2015) encontraram correlações positivas entre ambas as habilidades. Em síntese, os estudos recuperados são congruentes ao ressaltarem a importância da consciência metatextual para a aprendizagem da leitura e da escrita.

Referente aos instrumentos desenvolvidos para aferir a consciência metatextual, Spinillo (2009) destaca duas formas de avaliar essa habilidade. Uma delas sugere a identificação de elementos intratextuais referentes ao sentido de nexo e completude do texto, na qual a consciência metatextual é avaliada indiretamente. A outra é orientada aos fatores intertextuais e investiga a consciência metatextual de forma direta (Santos \& Cunha, 2012). Esta última tem como proposta a identificação de gêneros textuais distintos e será utilizada no presente estudo por meio da aplicação do Questionário de Avaliação da Consciência Metatextual (QACM). Nesse contexto, Santos e Cunha (2012), Spinillo e Almeida (2014) e Spinillo, Mota, e Correa (2010) alertam para a necessidade de aprofundar a investigação da consciência metatextual, no que se refere à sua associação com a compreensão de leitura (Barboza, 2014), com a identificação e produção de textos de gêneros textuais diversos (Spinillo \& Almeida, 2014), assim como na sua avaliação desde os primeiros anos da educação básica, por meio de instrumentos validados para esse fim (Cunha \& Santos, 2012).

Considerando os aspectos aqui abordados, o presente estudo se propôs à verificação das correlações existentes entre a compreensão de leitura e as habilidades metalinguísticas (consciência morfológica - flexional e derivacional - e a consciência metatextual). Adicionalmente, foram avaliadas as diferenças de desempenho dos alunos para as variáveis sexo e ano escolar.

\section{Método}

\section{Participantes}

A amostra de estudo contou com 71 alunos de uma escola pública do ensino fundamental I localizada no interior do estado de São Paulo, matriculados no $2^{\circ}, 3^{\circ}, 4^{\circ}$ e $5^{\circ}$ anos. As idades variaram entre sete e 10 anos $(M=8,32 ; D P$ $=1,09)$, sendo 41 meninas $(57,7 \%)$. O critério de inclusão foi a apresentação do Termo de Consentimento Livre e Esclarecido assinado pelos pais ou responsáveis.

\section{Instrumentos}

Teste de Cloze (Santos, 2005)

É um instrumento elaborado a partir da omissão dos quintos vocábulos de um texto com aproximadamente 250 palavras. Durante a aplicação o examinando é instruído a 
ler o texto atentamente e preencher os espaços com letras, sílabas ou palavras que lhe denotem um sentido. Nesta pesquisa aplicaram-se dois textos do teste de Cloze, a saber, "A princesa e o fantasma" (Cloze 1) e "Uma vingança infeliz" (Cloze 2). Ambos os textos foram organizados por Santos (2005), tendo como público-alvo os alunos do ensino fundamental. Em cada um dos textos foram eliminados 15 vocábulos. A correção adotada foi a literal, com a pontuação mínima de 0 e máxima de 15 pontos. Para a análise de dados adotou-se a soma dos dois textos, denominado de Cloze Total (pontuação mínima 0 ponto; máxima 30 pontos). Quanto as suas propriedades psicométricas, identificaram-se evidências de validade de critério em ambos os textos e o ano escolar (Mota \& Santos, 2014), inteligência (Santos, Sisto, \& Noronha, 2010) e a consciência fonológica (Suehiro \& Santos, 2015) e, ainda, evidências de validade por processo de resposta (Cunha \& Santos, 2009).

Tarefas de Avaliação da Consciência Morfológica TCM (Mota \& Brilhante, 2012)

Composta por duas séries de tarefas, sendo a primeira, de Analogia derivacional adaptada de Nunes, Bindman, e Bryant (1997) contendo uma série de 17 itens. Em cada item, a criança é orientada a formar uma palavra morfologicamente complexa a partir de uma palavra alvo. A segunda tarefa é a denominada de Analogia flexional também adaptada de Nunes e cols. (1997), composta por 19 itens, relacionados à concordância verbal, à flexão de número e à flexão de gênero. A tarefa requer que a criança identifique a modificação morfossintática em um par de palavras, para em seguida aplicá-la em outro par. A relação morfossintática entre as palavras deve ser mantida pelas crianças. Em relação ao critério de correção, em ambos os testes é contabilizada apenas uma resposta correta de cada sequência de itens. Assim, as Tarefas de Analogia Derivacional podem pontuar entre 0 a 17 pontos e as Tarefas de Analogia Flexional entre 0 e 19 pontos. No que se refere às propriedades psicométricas, estudos revelaram a consistência interna dos itens para as Tarefas de Analogia Derivacional $(\alpha=0,67)$ e para as Tarefas de Analogia Flexional $(\alpha=0,63)$. Conforme Mota e cols. (2013) esses índices não foram considerados adequados, porém nesses estudos, os instrumentos eram compostos por um número menor de itens.

Questionário de Avaliação da Consciência Metatextual - QACM - (Santos \& Cunha, 2012)

O instrumento é composto por 11 textos, nos quais o examinando é instruído a identificar seus respectivos gêneros textuais. Cada texto possui quatro opções de resposta. A compilação textual para a elaboração do instrumento abarcou alguns textos do programa 'Ler e Escrever' da Secretaria da Educação do Governo do Estado de São Paulo e do 'Programa de Formação de Professores Alfabetizadores', da Secretaria de Educação Fundamental do Ministério da Educação, Módulo 1, de Janeiro de 2001. Os demais foram adaptados ou elaborados para o instrumento com base nos textos utilizados pelos Parâmetros Curriculares Nacionais (Brasil, 1997) para o ensino fundamental I, Volume 2 - Língua Portuguesa. Quanto ao critério de correção, são consideras apenas as alternativas assinaladas corretamente pelo examinando. Assim, a pontuação pode variar de 0 a 11 pontos. Na análise da primeira versão do QACM foram encontradas evidências de validade de conteúdo, embasadas por meio da congruência e abrangência dos itens relacionados ao construto. Posteriormente, o teste foi aplicado individualmente numa amostra de 30 crianças, sendo solicitadas justificativas para suas escolhas. Por meio das respostas obtidas alguns textos foram modificados, já outros foram mantidos por serem compreendidos e por apresentarem uma linguagem adequada, possibilitando que fossem reconhecidos por elas.

\section{Procedimentos de coleta de dados}

Após a aprovação do Comitê de Ética da Universidade e o contato com a escola, foram emitidos os Termos de Consentimento Livre e Esclarecido para os pais ou responsáveis dos alunos. Posteriormente, com o retorno dos TCLEs assinados, os dias e os horários para a coleta de dados foram combinados mediante a apresentação de um cronograma à escola, o qual previa as aplicações dos instrumentos em duas partes. Na primeira aplicaram-se dois textos do Teste de Cloze e o Questionário de Avaliação da Consciência Metatextual (QACM) de forma coletiva, em sala de aula e sem tempo preestabelecido para o seu término. Já a segunda parte se deu com a aplicação das Tarefas de Avaliação da Consciência Morfológica Derivacional e Flexional individualmente, em um local designado pela escola. Também não foi estipulado ao aluno tempo máximo para a sua realização.

\section{Procedimentos de Análise de dados}

Após a correção dos instrumentos, os dados foram inseridos em uma planilha do Programa Package for Social Sciences (SPSS), versão 22.0, para serem submetidos às análises estatísticas. Aplicou-se a Análise Descritiva para encontrar a média e o desvio padrão dos participantes para as variáveis sexo e ano escolar. Utilizou-se a Análise de Correlação $r$ de Pearson para verificar as correlações existentes entre os três instrumentos. Para examinar as possíveis diferenças no desempenho das crianças quanto ao sexo, utilizou-se o Teste $t$ de Student. A fim de encontrar possíveis diferenças entre as médias dos participantes pela comparação dos alunos por ano escolar aplicou-se a Análise de Variância (ANOVA). Nesta análise também se solicitou o teste post hoc de Tukey, para separar os subgrupos segundo o desempenho nessas variáveis, com base nos escores médios apresentados pelos alunos nos instrumentos.

\section{Resultados}

Por meio do teste de correlação $r$ de Pearson verificou-se a existência de correlações significativas, positivas e 
Tabela 1. Valores da prova post hoc de Tukey para o desempenho entre os anos escolares para o Cloze Total, TCM Flexional e QACM.

\begin{tabular}{|c|c|c|c|c|}
\hline \multirow[b]{2}{*}{ Cloze Total } & \multirow[b]{2}{*}{$N$} & \multicolumn{3}{|c|}{ Subgrupos } \\
\hline & & 1 & 2 & 3 \\
\hline $2^{\circ}$ ano & 15 & 2,87 & & \\
\hline $3^{\circ}$ ano & 24 & & 7,75 & \\
\hline $4^{\circ}$ ano & 19 & & 11,89 & 11,89 \\
\hline $5^{\circ}$ ano & 13 & & & 13,00 \\
\hline$P$ & & 1 & 0,077 & 0,914 \\
\hline TCM Flexional & $N$ & 1 & 2 & 3 \\
\hline $2^{\circ}$ ano & 14 & 5,50 & & \\
\hline $3^{\circ}$ ano & 21 & & 9,14 & \\
\hline $4^{\circ}$ ano & 17 & & 11,71 & \\
\hline $5^{\circ}$ ano & 13 & & & 14,31 \\
\hline$P$ & & 1 & 0,201 & 0,190 \\
\hline QACM & $N$ & 1 & 2 & \\
\hline $2^{\circ}$ ano & 11 & 5,36 & & \\
\hline $3^{\circ}$ ano & 20 & & 8,40 & \\
\hline $4^{\circ}$ ano & 18 & & 9,28 & \\
\hline $5^{\circ}$ ano & 13 & & 10,46 & \\
\hline$P$ & & 1 & 0,050 & \\
\hline
\end{tabular}

moderadas para o teste de Cloze Total e as TCM Derivacional $(r=0,51 ; p<0,001)$ e Flexional $(r=0,68 ; p<0,001)$, e de forte magnitude para o Cloze Total e a QACM $(r=0,70 ; p$ $<0,001)$. Para a variável sexo não foram identificadas diferenças significativas de desempenho em nenhum dos instrumentos aplicados, sendo $p>0,05$, o que atribuí as médias aferidas ao acaso (Dancey \& Reidy, 2006).

No tocante à variável ano escolar, recorrendo à ANOVA detectaram-se diferenças significativas de desempenho para o Cloze Total, com $F=13,414(3,67) ; p<0,001$; TCM Flexional: $F=15,163(3,61) ; p<0,001$ e QACM: $F=15,163$ $(3,61) ; p<0,001$. Nesta análise, não foi encontrada diferença significativa apenas para a TCM Derivacional: $F=2,086$ $(3,61) ; p<0,111$. A Tabela 1 apresenta os resultados da prova post hoc de Tukey para a variável ano escolar.

Conforme observado na Tabela 1, verificou-se a separação por subgrupos de desempenho a partir das médias apresentadas pelos alunos. Os alunos do $5^{\circ}$ ano apresentaram maiores médias em compreensão de leitura e nas habilidades metalinguísticas avaliadas em comparação aos alunos do $4^{\circ}, 3^{\circ}$ e $2^{\circ}$ anos, respectivamente. No caso do QACM, as crianças do $2^{\circ}$ ano foram diferenciadas do restante, com um desempenho menor. Em relação à TCM Derivacional como não houve diferença estatisticamente significativa, o teste de Tukey não separou os grupos em função do ano escolar.

\section{Discussão}

As correlações aferidas entre as habilidades metalinguísticas (consciência morfológica - derivacional e flexional - e a consciência metatextual) e a compreensão de leitura confirmaram a hipótese inicial do estudo, no qual se proble- 
matizou sobre a existência de correlações entre as habilidades avaliadas. Assim, pressupõe-se que as habilidades metalinguísticas aferidas contribuem para com o domínio progressivo da compreensão de leitura e vice-versa.

No tocante à associação entre a compreensão de leitura e a consciência morfológica em alunos do Ensino Fundamental I, Mota e cols. (2009) identificaram correlações similares em tarefas análogas que avaliaram a consciência morfológica derivacional $(r=0,58)$ e flexional $(r=0,52)$, ambos com $p<0,001$. Guimarães e cols. (2014) também aferiram correlações positivas e moderadas $(r=0,42 ; p<0$, 001). Já em Freitas Junior e Mota (2015) verificou-se a existência de correlação apenas para a consciência morfológica flexional e a compreensão de leitura $(r=0,34 ; p<0,001)$.

Outras pesquisas também encontraram associações positivas entre a compreensão de leitura e a consciência metatextual no Ensino Fundamental I. Em Barboza (2014) foi identificado índice de correlação de magnitude moderada $(r=0,55 ; p<0,002)$ e, em Cunha e Santos (2012), as correlações situaram-se em torno de $r=0,68$ para o Cloze 1 e $r$ $=0,57$ para o Cloze $2(p<0,001)$. Em estudo posterior que objetivou conferir evidências de validade convergente para o QACM, Cunha e Santos (2015) constataram correlações de magnitude forte, a saber, Cloze 1: $\rho=0,70$ e Cloze 2: $\rho=$ $0,73(p<0,001)()$.

Considerando a variável sexo, verificou-se a ausência de diferenças significativas entre as médias dos alunos nos três instrumentos, podendo-se dizer que na amostra aqui focalizada, esta variável não foi um determinante para o desempenho em compreensão de leitura e nas habilidades metalinguísticas avaliadas. Embora em alguns estudos sobre a compreensão de leitura, tal diferença também não tenha sido identificada (Baliza \& Silva, 2015; Santos \& cols., 2010; Suehiro \& Boruchovitch, 2016), existem outros que apontam para a existência delas (Joly \& Istome, 2008; Oliveira, Boruchovitch, \& Santos, 2007). Relativo a comparações entre desempenhos em consciência morfológica e consciência metatextual não foram encontrados estudos empíricos que tenham controlado essa variável.

Em relação à variável ano escolar, as pesquisas com alunos do ensino fundamental I apresentam resultados semelhantes aos encontrados neste estudo. Nota-se que com o avanço dos anos escolares, os alunos demonstram um melhor desempenho conferido pela apresentação de médias superiores em compreensão de leitura no primeiro e segundo ciclos do ensino fundamental (Baliza \& Silva, 2015; Santos \& cols., 2010; Suehiro \& Boruchovitch, 2016), consciência morfológica derivacional e flexional (Guimarães \& cols., 2014), consciência morfológica derivacional (Miranda \& Mota, 2013) e, em consciência metatextual (Cunha \& Santos, 2015; Santos \& Cunha, 2012).

Sobre a compreensão de leitura, Baliza e Silva (2015) enfatizam a relevância em avaliá-la no decorrer dos anos escolares a fim de constatar se há realmente uma melhora no seu desempenho. Como mencionado, é esperado que com a progressão pelos diversos níveis da educação básica, o aluno adquira a proficiência nessa habilidade, em termos de, além de extrair e compreender o que é lido, ser capaz de elaborar analogias e inferências, uma vez que a compreensão de leitura também repercute no rendimento do aluno no contexto do ensino superior (Alcará \& Santos, 2015). Adicionalmente, Machado e Capellini (2016) destacam a eficácia de programas interventivos utilizando a técnica de Cloze como um meio para a promoção de melhorias em compreensão de leitura e na motivação do aluno para ler.

Em termos da consciência morfológica, se pressupõe que a partir do $2^{\circ}$ ano do ensino fundamental I o aluno já apresente algumas noções acerca dessa habilidade metalinguística, ou seja, demonstre a capacidade para analisar a estrutura da língua (Guimarães \& cols., 2014; Kruk \& Bergman, 2013). Nesse sentido, se pressupõe que a consciência morfológica tende a se desenvolver mediante o contato do aluno com a instrução formal, por meio da aplicação de tarefas que envolvam atividades específicas que estimulem os seus componentes derivacionais e flexionais, assim como pela aprendizagem da leitura (Kruk \& Bergman, 2013; Miranda \& Mota, 2013) e da escrita (Guimarães \& cols., 2014), visto que são habilidades que se correlacionam.

Para o desempenho em consciência metatextual, Santos e Cunha (2012) afirmam que os alunos dos anos escolares posteriores apresentam uma familiaridade maior com os gêneros textuais. Conjectura-se que isso pode ocorrer pelo contato do aluno com a instrução formal, pela busca por materiais de leitura diversos em seu cotidiano e, ainda, pelo domínio em compreensão de leitura, que viabiliza o discernimento e o reconhecimento de um número cada vez maior de gêneros textuais.

Considera-se relevante a realização de estudos sobre as habilidades linguísticas e metalinguísticas buscando ampliar o conhecimento sobre a potencial contribuição dessas habilidades no processo inicial da alfabetização (Mota \& cols., 2009), bem como as suas relações com a aprendizagem no decorrer da vida escolar e acadêmica do aluno. Pesquisas que abordam ambas as habilidades fomentam reflexões e fornecem dados para a análise daquilo que é aplicado em sala de aula atualmente, podendo fornecer elementos para uma atuação preventiva, a fim de evitar as dificuldades de aprendizagem em detrimento, por exemplo, de déficits em compreensão de leitura.

A partir de resultados análogos aos do presente estudo, apreende-se que a consciência morfológica está associada ao desempenho em compreensão de leitura, assim como da escrita. Guimarães e cols. (2014) descrevem que os alunos que pontuaram maiores escores em consciência morfológica também foram os que apresentaram maior quantidade de acertos ortográficos em atividades de produção textual e melhor desempenho em compreensão de leitura. A contribuição da consciência morfológica para as habilidades de compreensão de leitura e escrita é atribuída pelas autoras ao aspecto semântico atrelado à morfologia. Desse modo, compreende-se a atuação das unidades de significados ligados aos aspectos semânticos subjacentes ao desenvolvimento de ambas as habilidades, contrapondo-se à ideia do automatismo dos padrões ortográficos. 
Em um estudo longitudinal com alunos dos primeiros anos do nível elementar (correspondente ao primeiro ciclo do ensino fundamental no Brasil), Kruk e Bergman (2013) confirmaram a correspondência entre a consciência morfológica com as habilidades de leitura, compreensão de palavras isoladas e a compreensão de leitura. A partir da aplicação de testes que avaliaram esses construtos, os pesquisadores concluíram que a consciência morfológica pode ser considerada como uma habilidade metalinguística que facilita a aquisição e o desenvolvimento de habilidades que envolvem a leitura, desde o contato inicial do aluno com a instrução formal.

Tal contribuição advém dos aspectos semânticos, em especial a compreensão de palavras (atribuição de sentido) e sintáticos, caracterizado pela noção de organização das sentenças, ou seja, a estrutura do texto. Desse modo, se pressupõe que a consciência morfológica atue na elaboração de conexões semânticas e sintáticas, que por sua vez, estão vinculadas às representações lexicais. As representações dos morfemas-raiz e dos afixos contribuem para o reconhecimento do significado e das relações entre as palavras, possibilitando com que o aluno as analise, auxiliando-o em tarefas que envolvam a leitura (Kruk \& Bergman, 2013).

No que corresponde à correlação aferida entre a consciência metatextual e a compreensão de leitura, Santos e Cunha (2012) discutem os benefícios em desenvolvê-las mutuamente. Esse processo pode ocorrer a partir de iniciativas que mobilizem a coordenação da escola e os seus professores na promoção do contato do aluno com diversos gêneros textuais desde os primeiros anos do ensino fundamental. Acredita-se que, ações similares a essa direcionem o aluno para que analise a estrutura do texto e compreenda a mensagem transmitida a partir da percepção do seu gênero textual.

Ressalta-se, ainda, a relevância dos estudos que competem à investigação da consciência metatextual e a compreensão de leitura em relação ao ano escolar. Essa avaliação corrobora para que sejam identificados os critérios adotados pelos alunos na identificação e produção de gêneros textuais nos diversos anos escolares. Compreendendo aspectos que podem ser alterados, pode-se contribuir para com a melhora do desempenho escolar especialmente no contexto do ensino público, alvo do presente estudo (Santos \& Cunha, 2012; Spinillo \& Almeida, 2014).

Por fim, em relação às limitações deste estudo, primeiramente se reconhece o número restrito da composição da amostra, provenientes de apenas um tipo de escola e região do país, sendo futuramente interessante a comparação do desempenho das habilidades avaliadas em alunos da rede particular de ensino e de outras regiões. Outro ponto a ser destacado, com ênfase para a avaliação da consciência morfológica, seria o controle da consciência fonológica, habilidade metalinguística essa também associada à leitura e compreensão de leitura (Mota \& cols., 2009) e, a inclusão das consciências semântica e sintática (Kruk \& Bergman, 2013). Finalmente, destaca-se a pertinência no investimento de estudos que investiguem as habilidades aqui avaliadas, principalmente no que se refere à consciência morfológica derivacional (Miranda \& Mota, 2013) e a consciência meta- textual (Santos \& Cunha, 2012) em razão de desempenho e contribuição com o processo de ensino e aprendizagem.

\section{Referências}

Alcará, A. R.; Santos, A. A. A. D. (2015). Avaliação e desenvolvimento da compreensão de leitura em universitários. Estudos de psicologia (Campinas), 32(1), 63-73. doi:10.1590/0103-166X2015000100006

Albuquerque, E. B. C.; Spinillo, A. G. (1997). O conhecimento de crianças sobre diferentes tipos de textos. Psicologia: Teoria e Pesquisa, 13, 329-338.

Albuquerque, E. B. C.; Spinillo, A. G. (1998). Consciência textual em crianças: critérios adotados na identificação de partes de textos. Revista de Estudios e Investigación en Psicología y Educación, 3, 145-158. Recuperado: 10 abr. 2016. Disponível: http://ruc.udc.es/ bitstream/2183/6673/1/RGP_3-10.pdf

Baliza, A. A.; Silva, D. V. (2015). Avaliação da compreensão em leitura a estudantes do ensino fundamental. Lumen: Educare, 1(1). Recuperado: 21 nov. 2016. Disponível: http://revistas.unasp.edu. br/lumen/article/view/579

Barboza, L. D. S. (2014). A relação entre compreensão leitora e consciência textual: um estudo com alunos de $2^{\circ}$ e $3^{\circ}$ anos do ensino fundamental. Dissertação de Mestrado, Pontifícia Universidade Católica, Porto Alegre: Rio Grande do Sul. Recuperado: 03 mar. 2016. Disponível: http://meriva.pucrs.br/ dspace/handle/10923/5761

Barrera, S. D.; Maluf, M. R. (2003). Consciência metalinguística e alfabetização: um estudo com crianças da primeira série do ensino fundamental. Psicologia: Reflexão e Crítica, 16(3), 491502. Recuperado: 12 nov. 2015. Disponível: http://www.scielo.br/ pdf/\%0D/prc/v16n3/v16n3a08.pdf

Basílio, M. M. (2009). Morfologia: uma entrevista com Margarida Basílio. ReVEL, 12 (7). Recuperado: 08 ago. 2016. Disponível: http://www.revel.inf.br/files/entrevistas/revel_12_margarida_ basilio.pdf

Brasil. (1997). Secretaria de Educação Fundamental. Parâmetros Curriculares Nacionais: Português. Brasília: MEC/SEF. Recuperado de http://portal.mec.gov.br/seb/arquivos/pdf/livro02.pdf

Capovilla, A. G. S.; Capovilla, F. C.; Soares, J. V. T. (2004). Consciência sintática no ensino fundamental: correlações com consciência fonológica, vocabulário, leitura e escrita. Psico-USF, 9 (1), 39-45. Recuperado: 10 set. 2016. Disponível: http://www.scielo.br/pdf/ pusf/v9n1/v9n1a06.pdf

Corso, H. V.; Salles, J. F. (2009). Relação entre leitura de palavras isoladas e compreensão de leitura textual em crianças. Letras de Hoje, 44(3), 28-35. Recuperado: 10 set. 2016. Disponível: http://revistaseletronicas.pucrs.br/ojs/index.php/fale/article/ 
view/5761/4181

Cunha, V. L. O. (2012). Perfil de escolares do $3^{\circ}$ ao $5^{\circ}$ ano do ensino fundamental I em compreensão de leitura: elaboração de instrumento avaliativo. Tese de Doutorado, Faculdade de Filosofia e Ciências: Marília-SP. Recuperado: 13 nov. 2016. Disponível: http://repositorio.unesp.br/handle/11449/10221트

Cunha, N. B.; Santos, A. A. A. (2008). Habilidades lingüísticas no ensino fundamental em escolas públicas e particulares. PSIC Revista de Psicologia da Vetor Editora, 9(1), 35-44. 10 nov. 2016. Recuperado: Disponível: http://pepsic.bvsalud.org/pdf/psic/v9n1/ v9n1a05.pdf

Cunha, N. B.; Santos, A. A. A. (2015). Avaliação da consciência metatextual: um instrumento de medida. Revista de Estudios e Investigación en Psicología y Educación, (10), 137-141. doi: 10.17979/reipe.2015.0.10.922

Cunha, N. D. B.; Santos, A. A. A.D. (2009). Validade por processo de resposta no teste de Cloze. Fractal: Revista de Psicologia, 21(3), 549-562. Recuperado: 15 ago. 2016. Disponível: http://www.uff.br/ periodicoshumanas/index.php/Fractal/article/view/162/364

Dancey, C. P.; Reidy, J. (2006). Estatística sem matemática para psicólogos. Porto Alegre: Artes Médicas.

Freitas Junior, P. V. D.; Mota, M. M. P. E. D. (2015). So, Morphological Awareness Contributes to Reading in Brazilian Portuguese?. PsicoUSF, 20(3), 471-480. doi.org/10.1590/1413-82712015200309

Guimarães, S. R.; Paula, F. V.; Mota, M. M. P. E.; Barbosa, V. R., (2014). Consciência morfológica: que papel exerce no desempenho ortográfico e na compreensão de leitura? Psicologia USP, 25(2), 201-212. https://dx.doi.org/10.1590/0103-6564A20133713

Gombert, J. E. (1992). Metalinguistic development. Chicago: University of Chicago Press. [e-book].

Gomes, M. A. M.; Boruchovitch, E. (2009). Proficiência em leitura: um panorama da situação. In: Santos, A. A. A.; Boruchovitch, E.; Oliveira, K. L. (Orgs.), Cloze: um instrumento de diagnóstico e intervenção (pp. 23-46). São Paulo: Casa do Psicólogo.

Joly, M. C. R. A.; Istome, A.C. (2008). Compreensão em leitura e capacidade cognitiva: Estudo de validade do Teste Cloze BásicoMAR. Psic: revista da Vetor Editora, 9(2), 219-228. Recuperado: 20 nov. 2016. Disponível: http://pepsic.bvsalud.org/pdf/psic/v9n2/ v9n2a10.pdf

Kruk, R. S.; Bergman, K. (2013). The reciprocal relations between morphological processes and reading. Journal of Experimental Child Psychology, 114(1), 10-34. Doi: 10.1016/j.jecp.2012.09.014

Lucio, P. S.; Moura, R. J.; Nascimento, E.; Pinheiro, A. M. V. (2012). Construção de uma tarefa de leitura em voz alta de palavras: análise psicométrica dos itens. Psicologia: Reflexão e Crítica,
25(4), 662-670. Recuperado de http://www.scielo.br/pdf/prc/ v25n4/05.pdf

Machado, A. C.; Capellini, S. A. (2016). Dados preliminares de um programa de intervenção para compreensão leitora por meio da técnica de cloze. Revista Psicopedagogia, 33(101), 144-153. Recuperado: 21 nov. 2016. Disponível: http://pepsic.bvsalud.org/ pdf/psicoped/v33n101/04.pdf

Miranda, L. C.; Mota, M. M. P. E. D. (2013). Há uma relação específica entre consciência morfológica e reconhecimento de palavras? PsicoUSF, 18(2), 241-247. doi.org/10.1590/S141382712013000200008

Mota, M. M.P. E. D. (2012). Explorando a relação entre consciência morfológica, processamento cognitivo e escrita. Estudos de Psicologia (Campinas), 29(1), 89-94. doi.org/10.1590/S0103166X2012000100010

Mota, M. M. P. E.; Anibal, L.; Lima, S. (2008). A morfologia derivacional contribui para a leitura e escrita no português? Psicologia: Reflexão e Crítica, 21(2), 311-318. Recuperado: 10 jul. 2016. Disponível: http://www.scielo.br/pdf/prc/v21n2/a17v21n2.pdf

Mota, M. M. P. E.; Brilhante, S. (2012). Tarefas de consciência morfológica. Relatório técnico não publicado. Rio de Janeiro; UERJ.

Mota, M. M. P. E.; Guimarães, S. B.; Conti, C.; Linhares, T.; Rezende, L. B.; Amorin, S.; Coelho, L.; Badaró, A.; Gumier, A. B. (2013). Diferenças entre o desenvolvimento da morfologia derivacional e flexional no português brasileiro no ensino fundamental. Psicologia: Reflexão e Crítica, 26 (4), 730-734. Recuperado: 19 nov. 2016. Disponível: http://www.scielo.br/pdf/prc/v26n4/13.pdf

Mota, M. M. P. E. D.; Lisboa, R.; Dias, J.; Gontijo, R.; Paiva, N.; Mansur-Lisboa, S.; Silva, D. A.: Santos, A. A. A. D. (2009). Relação entre consciência morfológica e leitura contextual medida pelo teste de Cloze. Psicologia Reflexão e critica 22(2), 223-229. doi. org/10.1590/S0102-79722009000200008

Mota, M. M. P. E. D.; Santos, A. A. A. (2014). The Cloze evaluation as a measure of reading ability in primary education. Psicologia Escolar e Educacional, 18(1), 135-142. doi.org/10.1590/S141385572014000100014

Nunes, T.; Bindman, M.; Bryant, P. (1997). Morphological strategies: developmental stages and processes. Developmental Psychology, 33(4), 637-649. doi: 10.1037/0012-1649.33.4.637

Oliveira, K. L.; Boruchovitch, E.; Santos, A. A. A. (2009). A técnica de cloze na avaliação da compreensão de leitura. In: Santos, A. A. A.; Boruchovitch, E.; Oliveira, K. L. (Orgs.), Cloze: um instrumento de diagnóstico e intervenção. (pp. 47-78). São Paulo: Casa do Psicólogo.

Oliveira, K. L. D.; Boruchovitch, E.; Santos, A. A. A. D. (2007), 
Compreensão de leitura em alunos de sétima e oitava séries do ensino fundamental. Psicologia Escolar e Educacional, 11(1), 4149. Recuperado: 18 ago. 2015. Disponível: http://pepsic.bvsalud. org/pdf/pee/v11n1/v11n1a05.pdf

Santos, A. A. A. (2005). Evidências e validade de critério para o Teste de Cloze. (Manuscrito não publicado). Programa de Pósgraduação Stricto-Sensu em Psicologia da Universidade São Francisco: Itatiba, SP.

Santos, A. A. A.; Boruchovitch, E.; Oliveira, K. L. (2009). Cloze: Um instrumento de diagnóstico e intervenção ( $1^{\mathrm{a}}$ ed.). São Paulo: Casa do Psicólogo.

Santos, A. A. A.; Cunha, N.D.B. (2012). Consciência metatextual: evidências de validade para instrumento de medida. Psico USF, 17(2), 233-241. doi.org/10.1590/S1413-82712012000200007

Santos, A. A. A.; Primi, R.; Taxa, F. O. S.; Vendramini, C. M. (2002). O teste de Cloze na avaliação da compreensão em leitura. Psicologia: Reflexão e Crítica, 15(3), 549-560. Recuperado: 18 nov. 2015. Disponível: http://www.scielo.br/pdf/prc/v15n3/a09v15n3

Santos, A. A. A.; Santos, E. C. P. (2015). Avaliação de um programa de intervenção para o ensino do espanhol. Paradigma, 23(2), 4975. Recuperado: 21 nov. 2016. Disponível: http://revistas.upel. edu.ve/index.php/paradigma/article/view/2888

Santos, M. J.; Barrera, S. D. (2015). Escrita de textos narrativos sob diferentes condições de produção. Psicologia Escolar e Educacional, 19(2), 253-260. doi.org/10.1590/2175$3539 / 2015 / 0192827$

Santos, A. A. A.; Sisto, F. F.; Noronha, A. P. P. (2010). Toni 3-Forma A e teste de Cloze: evidências de validade. Psicologia: Teoria e Pesquisa, 26(3), 399-405. Recuperado: 13 nov. 2016. Disponível: http://www.scielo.br/pdf/ptp/v26n3/a02v26n3.pdf

Spinillo, A. G. (2009). A consciência metatextual. In: Mota, M. (Org.), Desenvolvimento metalinguístico: questões contemporâneas (pp.
77-114). São Paulo: Casa do Psicólogo.

Spinillo, A. G.; Almeida, D. D. (2014). Compreendendo textos narrativo e argumentativo: há diferenças? Arquivos Brasileiros de Psicologia, 66(3), 115-132. Recuperado: 21 nov. 2016. Disponível: http://revistas.upel.edu.ve/index.php/paradigma/article/view/2888

Spinillo, A. G.; Mota, M. M. P. E.; Correa, J. (2010). Consciência metalinguística e compreensão de leitura: diferentes facetas de uma relação complexa. Educar em Revista, 38(3), 157-171. Recuperado: 13 nov. 2016. Disponível: http://www.scielo.br/pdf/er/ n38/11.pdf

Spinillo, A. G.; Simões, P. U. (2003). O desenvolvimento da consciência metatextual em crianças: questões conceituais, metodológicas e resultados de pesquisas. Psicologia: Reflexão e Crítica, 16(3), 537-546. Recuperado: 21 nov. 2016. Disponível: http://www.scielo.br/pdf/prc/v16n3/v16n3a12

Suehiro, A. C. B.; Santos, A. A. A. (2015). Compreensão de leitura e consciência fonológica: evidências de validade de suas medidas. Estudos de Psicologia (Campinas), 32(2), 201-211. doi. org/10.1590/0103-166X2015000200005

Suehiro, A. C. B.; Boruchovitch, E. (2016). Reading Comprehension for Students from the Third and Fourth Cycles of Basic Education. Psico-USF, 21(3), 561-572. doi.org/10.1590/141382712016210310

Torres, M.; Roig, M. (2005). The Cloze procedure as a test of plagiarism: the influence of text readability. Journal of Psychology, 139(3), 221-331. doi: 10.3200/JRLP.139.3.221-232

Williams, R. S.; Ari, O.; Santamaria, C. N. (2011). Measuring college students' reading comprehension ability using cloze tests. Journal of Research in Reading, 34(2):215-31. doi/10.1111/j.14679817.2009.01422.x/pdf
Recebido em: 22 de fevereiro de 2017 Aprovado em: 07 de dezembro de 2017

(cc) EY License information: This is an open-access article distributed under the terms of the License (type CC-BY), which permits unrestricted use, distribution and reproduction in any medium, provided the original article is properly cited. 